J OURNAL OF French and Francophone Philosophy
RE V UE DE LA

philosophie française et de langue française

\title{
Lettre à Néméla
}

\section{Albert Memmi}

Journal of French and Francophone Philosophy - Revue de la philosophie française et de langue française, Vol XIX, No 2 (2011) pp 7-8

\author{
Vol XIX, No 2 (2011) \\ ISSN 1936-6280 (print) \\ ISSN 2155-1162 (online) \\ DOI $10.5195 /$ jffp. 2011.505 \\ www.jffp.org
}

\section{(cc) EY-NC-ND}

This work is licensed under a Creative Commons Attribution-Noncommercial-No Derivative Works 3.0 United States License.

\section{ULIS D-Sunt}

This journal is operated by the University Library System of the University of Pittsburgh as part of its D-Scribe Digital Publishing Program, and is co-sponsored by the University of Pittsburgh Press 


\section{Lettre à Néméla}

\section{Albert Memmi}

Paris, le 26 mai 2011

Ma chère Néméla,

Il s'est produit un quiproquo amusant. Ce que je voulais te dire dans cette lettre, je me suis dit que je pourrais m'en servir pour cette allocution inopinée. Puis on m'a averti que je ne disposerai que de quelques minutes. Me voici donc renvoyé à ce que je voulais te dire, et que je n'ai pas dit l'autre soir. Tant pis pour les organisateurs et le public.

En fait, par ta lettre-poème, tu m'as montré que tu avais parfaitement aperçu quelle était la matrice et l'essentiel de mon œuvre: c'est le sentiment, fortement vécu, et ancré, qu'il ya des injustices presque partout, que des gens en souffrent et qu'il faut, qu'il me faut les combattre: tel est d'ailleurs le sens du contrat social, implicite ou explicite. C'est pourquoi les humains se groupent: pour que chacun trouve son compte dans l'association. Malheureusement (tel est l'homme) il y a les habiles qui cherchent à en avoir plus, même au détriment des autres membres, et aussi les groupes euxmêmes, qui deviennent cancéreux en quelque sorte, et spolient, écrasent les individus.

Il en résulte, pour moi, une philosophie, une éthique et une méthode.

La philosophie, ce que j'entends par philosophie est la lutte pour la solidarité conquise, retrouvée. Mais une solidarité sans complaisance, ni compromission, sans quoi elle serait mensongère. Et ce n'est pas rendre services aux démunis (et aux siens propres) que de ne pas leur dire l'exacte vérité.

Donc, d'abord, rechercher sans cesse la vérité puis tenter de la communiquer. Les deux démarches ne vont pas toujours de pair. On peut ne pas arriver à communiquer la vérité, quelque fois parce qu'il ya péril à le faire. Descartes, Spinoza ont décidé de garder dans un tiroir leurs sommes. D'autres ont été torturés, emprisonnés pour avoir eu l'audace de manifester la vérité. 
Mais, tous comptes faits, telle est la "mission" du penseur. Pour cela il doit sans cesse suivre les enseignements de la raison: se méfier donc des préjugés (ceux de son groupe aussi!) et des utopies. Les utopies sont une forme de mensonge collectif (les religions, les idéologies, les tactiques).

Seulement ainsi il pourrait atteindre un humanisme véritable, ce qui est tout simplement que c'est l'homme qui est le plus important, non les groupes, les intérêts, les illusions de toutes sortes, les causes prétendument sensées. Est sacré ce que nous prétendons tel; il n'est fondé sur rien.

En passant: n'y a-t-il pas de place pour la fiction? N'ai-je pas moi-même redigé et publié des récits et même des poèmes? Mais la fiction sert à exprimer, à suggérer ce que l'on est incapable de rendre par les concepts: ponctuellement les émotions, le sentiment de l'inconnu. Comment dire par des concepts le trouble que suscite la feminité (ou la masculinité pour les femmes, je suppose), l'attendrissement devant un enfant? Les arts, la poésie, sont à notre disposition pour cela. En bref, avoir recours à la fiction mais en sachant, se rappelant sans cesse qu'il s'agît de fictions et que c'est la raison qui doit, en dernier recours, décider, d'ailleurs sur la base d'expérimentations réfléchies et collectivement controlées.

Donc, toujours partir du réel, conceptualiser après. Eventuellement se proposer des outils; ce que j'ai tenté de faire avec le concept de judéité, qui a eu la chance d'être adopté par le dictionnaire, ou celui d'hétéropathie, la notion de duo (qui a fondé mon travail sur les dépendances, après celui des dominances).

D'où, pour terminer cette trop longue lettre, mes "engagements" politiques: ils ne sont jamais fondés sur des complaisances ou des équivoques. Cette rigueur n'est pas toujours comprise, ainsi pour la laïcité. Tant pis, j'aurai fait mon métier.

Je dois avouer que cela me procure aussi quelque "contentement"; c'est ainsi que j'ai rédigé trois petits ouvrages sur le bonheur possible. Je n'ai ni dédain ni avidité pour les biens, mais une tendance à rechercher quelque sérénité, si elle est possible, dans les "petits bonheurs."

Pardonne-moi d'avoir été long, mais j'ai essayé de rendre cohérentes les réponses à tes questions. Et que tu as devinées ! et qui se trouvent aussi dans ta lettre-poème.

Et ce qui se trouve, en plus, je te l'ai dit dans ma précédente lettre, c'est ton approbation, qui m'a fortifié.

Merci donc.

Affectueusement. 